\title{
Notícias televisivas e públicos infantis: o porquê da aposta em jornalismo segmentado para as crianças
}

\section{TV news and children`s audiences: why the bet on segmented journalism for children}

\author{
Patrícia Silveira*
}

*Faculdade de Design, Tecnologia e Comunicação (IADE) - Universidade Europeia, Lisboa; Faculdade de Ciências Humanas (FCH) - Universidade Católica Portuguesa, Lisboa; Centro de Estudos de Comunicação e Sociedade (CECS) Universidade do Minho, Braga

Resumo

\begin{abstract}
Estudos recentes documentam a presença das notícias no quotidiano dos públicos infantis, mostrando que estes conteúdos são importantes para o seu conhecimento do mundo e a sua socialização (AlonTirosh \& Lemish, 2014; Delorme, 2013; Silveira, 2019). No contexto português, são ainda escassas as pesquisas desenvolvidas sobre esta problemática, pelo que desenvolvemos este estudo com o objetivo de analisar a natureza das interações entre as crianças e as notícias. Metodologicamente, esta investigação envolveu a aplicação de inquéritos por questionário e a dinamização de grupos de foco junto de crianças a frequentar o ensino primário nas escolas do Concelho de Paredes (Distrito do Porto). Os resultados mostram que as crianças contactam habitualmente com a atualidade, sobretudo pela televisão, juntamente com a família, embora demonstrem pouco interesse em seguir certas notícias. Os resultados evidenciam que as crianças desejam contactar com notícias mais adequadas aos seus gostos e às suas capacidades de compreensão. Posto que a televisão se constitui como o meio privilegiado para as famílias e, consequentemente, os públicos infantis, acompanharem a atualidade, julgamos que as conclusões apontadas no artigo poderão servir para informar as empresas mediáticas e outros agentes sobre aspetos a considerar no desenvolvimento de espaços informativos concebidos para os mais novos.
\end{abstract}

Palavras-chave: crianças; perceções; notícias; media; televisão.

Abstract

Recent studies document the presence of news in children's daily lives, showing that they are important for their knowledge of the world and their socialization (Alon-Tirosh \& Lemish, 2014, Delorme, 2013; Silveira, 2019). It Portugal, there are few researches on this problematic. For this reason, this article intends to analyse the interactions between the children and the news. Methodologically, this research involved the application of questionnaires and the dynamization of focus groups with children attending primary school, in Paredes (District of Porto). The results show that children follow usually current events, especially within television, with the family, although they show little interest in following these subjects. These audiences wish to follow more interesting and appropriate themes. Given that television is the favourite medium for following the news by the families, and the children, we believe that this study could inform media companies and other agents about aspects to be considered in the development of information spaces designed for the youngest.

Keywords: children; perceptions; news; media; television.

Submitted: $11^{\text {th }}$ February 2019

Accepted: $31^{\text {st }}$ March 2019

\section{How to quote this article:}

Silveira, P. (2019). Notícias televisivas e públicos infantis: o porquê da aposta em jornalismo segmentado para as crianças. Observatorio, 13(2), 48-67. 


\section{Introdução sobre as práticas de acesso e de consumo noticioso por crianças}

O envolvimento dos públicos infantojuvenis com os conteúdos noticiosos tem-se constituído como objeto de estudo de investigadores de áreas diversas. Preocupados em compreender e analisar as interações entre os mais novos e as notícias, estas investigações enfatizam o lugar que os conteúdos informativos ocupam no quotidiano das crianças e a implicação que têm para os seus modos de estar no mundo e de compreendêlo (Alon-Tirosh \& Lemish, 2014; Delorme, 2013; Lemish, 2007; Silveira, 2016, 2019). De acordo com estas pesquisas, estes públicos procuram acompanhar as notícias para estar a par dos acontecimentos da sociedade e do mundo, no entanto, nestas enfatiza-se também a necessidade de existirem espaços informativos que sejam mais adequados aos interesses e às capacidades de entendimento dos mais novos (Condeza et al., 2014; Nikken \& Götz, 2007). As investigações sugerem que a atualidade faz parte do quotidiano das crianças e que estas audiências seguem habitualmente estes assuntos na companhia dos pais e de outros familiares, particularmente através da televisão (Delorme, 2013; Gunter et al., 2000; Kruuse \& Kalmus, 2016; Silveira, 2016; 2019). Apesar dos avanços tecnológicos e da facilidade de acesso às notícias através das novas plataformas mediáticas, a televisão continua a ser o médium preferido de contacto com as temáticas da atualidade, pelas famílias, facilitando o acesso das crianças a estes conteúdos (Condeza et al., 2014; Götz, 2007; Hujanen \& Pietikäinen, 2004; Molen \& Konijn, 2007).

Uma pesquisa qualitativa desenvolvida junto de crianças e jovens finlandeses, sobre os consumos informativos destas audiências, concluiu que apesar das possibilidades interativas oferecidas pelos novos media, potenciadoras de novos modos de consumo de informação e de participação, a maioria das crianças e jovens continua a preferir acompanhar a atualidade a partir dos media tradicionais, nomeadamente da televisão e dos jornais (Hujanen \& Pietikäinen, 2004). Apesar de os mais jovens estarem familiarizados com as novas tecnologias comunicativas e de reconhecerem as vantagens (rapidez, facilidade na utilização e possibilidade de participação online) de recorrer a estes meios para contactar com a atualidade, estes são usadas para outros fins (idem). Resultados semelhantes foram obtidos a partir da investigação realizada em contexto português, The news and its impact on Portuguese children's perspectives (Silveira, 2019), que concluiu que a televisão ocupa um lugar privilegiado no espaço doméstico enquanto fonte dos acontecimentos do mundo, fazendo com que as crianças sigam estes assuntos frequentemente em momentos de reunião familiar, como os dedicados às refeições.

Apesar de os estudos demonstrarem que as notícias estão presentes na vida dos mais pequenos, isso não significa que as crianças escolham acompanhar estes conteúdos. Dafna lemish (2007), especialista destas questões, refere que as crianças têm pouca ou nenhuma motivação para acompanhar as notícias, uma vez que estas não satisfazem os seus interesses e necessidades, perturbam o seu horário habitual de programas, são repetitivas e exercem um forte impacto emocional, particularmente sobre as raparigas. Há, também, investigações que concluíram que as crianças consideram que os conteúdos transmitidos e os formatos dos programas de notícias não são adequados à sua idade (Alon-Tirosh \& Lemish, 2014), demonstrando que o seu interesse para seguir as notícias seria maior caso se operassem algumas mudanças, nomeadamente ao nível da linguagem utilizada, da forma de cobertura dos eventos e da utilização de ilustrações ou de imagens mais apelativas, do tipo de tópicos abordados (mais educacionais e informativos), e da descentralização dos conteúdos versados em acontecimentos trágicos e potencialmente assustadores e antieducativos para os públicos mais jovens (idem). As crianças consideram, também, que há certos eventos transmitidos pelas 
notícias, sobretudo na televisão, que Ihes provocam elevado impacto emocional (como raiva, medo, preocupação e ansiedade), demostrando o desejo de contactarem com acontecimentos mais positivos e com alguns pontos de humor (Alon-Tirosh \& Lemish, 2014).

É com base nas premissas apresentadas que esta investigação tem como objeto de estudo as interações entre os públicos infantis e as temáticas da atualidade, procurando argumentar sobre a necessidade de existirem conteúdos de teor informativo que sejam direcionados para este segmento. Por via da combinação de metodologias quantitativas e qualitativas, nomeadamente da administração de inquéritos por questionário e da dinamização de grupos de foco, junto de crianças portuguesas a frequentar o $4^{\circ}$ ano de escolaridade do Ensino Básico, procurou compreender-se e analisar-se, a partir da perspetiva destes públicos, as suas práticas de acesso e de consumo de notícias, e as apropriações que fazem destes conteúdos. Enfatiza-se o olhar sobre a receção noticiosa e, em particular, a necessidade de as pesquisas darem espaço para que os mais pequenos possam integrar-se como sujeitos de investigação, dando conta, na primeira pessoa, das suas opiniões e pontos de vista em relação às suas experiências com os media e, neste caso, a informação noticiosa.

\section{Jornalismo para a infância: o caso português}

Este artigo tem como pano de fundo a importância de haver investimento em espaços de informação da atualidade concebidos particularmente para os públicos infantis. Sabemos, sobretudo a partir de casos de sucesso internacionais (como o Newsround ou o Dogo News), que estes espaços se constituem como uma notável fonte de informação sobre os acontecimentos locais e globais, e têm como preocupação a produção de notícias que sejam adequadas aos públicos mais jovens. Ao mesmo tempo, há quem os veja como uma forma de estímulo para o aumento do interesse sobre a atualidade, para a formação de uma opinião esclarecida sobre as questões da sociedade, e para o desenvolvimento de competências críticas em relação aos media, podendo incentivar a uma maior intervenção no espaço público (Silveira, 2016). Os autores que investigam estas questões têm vindo a sublinhar as vantagens de se investir na produção de espaços noticiosos dirigidos aos mais novos, considerando que se trata de uma forma de introduzir as crianças nas questões habitualmente vistas como fazendo parte do "mundo dos adultos", como a política e a economia, uma vez que a informação sobre estes tópicos é produzida a pensar especificamente nos mais jovens e nas sua capacidades de entendimento (Carrero, 2008; Nikken \& Götz, 2007). Além disso, os autores sublinham que quem produz estes conteúdos tem a preocupação para com os efeitos decorrentes da exposição a determinados assuntos potencialmente perturbadores (relacionados com crime e violência), adotando estratégias que permitem prevenir esse impacto negativo e minimizar possíveis consequências para as crianças (Molen \& Vries, 2003).

Particularmente na televisão, estes formatos de teor informativo poderiam ganhar o seu espaço nas grelhas de programação. Como notamos a partir dos resultados apresentados por vários autores (Araus, 2011; Endestad et al., 2011; Rebelo et al., 2008), a televisão continua a ocupar um lugar privilegiado no quotidiano das crianças e no seu entendimento do mundo, ainda que se assista progressivamente à proliferação das novas tecnologias e à facilidade no acesso dos mais novos a estas plataformas (Endestad et al., 2011; Garmendia et al., 2012). Os novos media poderão ter revolucionado as formas de "ver televisão", no entanto, 
não vieram retirar importância, no que às audiências infantis diz respeito, aos conteúdos disponibilizados pelas empresas do setor televisivo (Rebelo et al., 2008). Pelo contrário, estudos recentes demonstram que a consolidação da televisão digital terrestre (TDT) e a posterior democratização no acesso das famílias aos canais com serviços por subscrição vieram transformar o consumo televisivo infantil, observando-se o aumento do consumo televisivo pelas crianças, sobretudo nos canais temáticos com programação direcionada especificamente a este segmento (Araus, 2011).

Dados da ANACOM (Autoridade Nacional de Comunicações) sugerem que, em Portugal, há uma tendência de crescimento do número de assinantes de televisão por subscrição. Dados do primeiro semestre de 2018 apontam para um total de 3,9 milhões de assinantes destes serviços (+ 3,5\% face ao semestre homólogo), e para a presença de $78,4 \%$ de lares com acesso a mais de 100 destes canais. Alguns destes, como o Panda, o Panda Biggs, o Disney Junior, o Jim Jam, entre outros, destinam-se concretamente às audiências infantojuvenis. Na atualidade, não há estudos consolidados sobre a análise da programação para a infância nos canais temáticos e, por outro lado, as práticas de receção destes conteúdos pelas audiências infantis, no entanto, na dissertação de mestrado apresentada em 2008, na qual analisou cinco destes canais durante o ano de 2005, Sandra Tavares verificou que os mesmos oferecem novos tipos de programação aos mais novos e podem apresentar-se como uma importante alternativa à programação disponível nos canais generalistas, uma vez que a programação infantil passa a estar acessível durante todo o dia e deixa de estar limitada "às pressões horárias dos canais e à gestão de espaços de emissão televisiva" (Tavares, 2008: 98). Um dos pontos que nos interessa particularmente, prende-se com o tipo de programação que estes canais disponibilizam aos mais novos, já que importa perceber, no contexto deste artigo, se há oferta de espaços de informação da atualidade, ou se, pelo contrário, estes se encontram ausentes ou são relegados para segundo plano, em detrimento de outro tipo de conteúdos. Apesar de, como Tavares (2008) refere, a ideia de programação diversificada abranger não apenas conteúdos que vão ao encontro de diferentes gostos e preferências, mas também diversos géneros televisivos (como o lúdico, o educativo, o ficcional, o informativo, entre outros), as conclusões do seu estudo apontam para a predominância das séries animadas, de produção norte-americana, e especial atenção para com um público-alvo entre os 6 e os 11 anos de idade. Os espaços informativos que se preocupem em explicar às crianças as questões do mundo atual, parecem não ser uma aposta destes canais, que privilegiam, sobretudo, os conteúdos lúdicos.

Apesar do crescimento, em anos recentes, do número de canais temáticos dirigidos à infância, não parece existir investimento em estudos empíricos que analisem a programação que oferecem, no entanto, um olhar atento sobre as suas grelhas de programação, acessíveis online, permite observar que, no que à informação de atualidade diz respeito, parece que continua a existir ausência de programas que se dediquem a estes assuntos, em detrimento de outros, mais vocacionados para o entretenimento. Será esta, também, uma tendência dos canais hertzianos nacionais? Sabemos que apesar da possibilidade de acesso das crianças aos canais com programação dirigida a si, 24 horas por dia, os mais novos não deixaram de acompanhar a programação disponível nos canais generalistas nacionais, como têm vindo a demonstrar estudos desenvolvidos nos últimos anos (Pereira et al., 2009; Rebelo et al., 2008). Além disso, é necessário chamar a atenção para o facto de o acesso aos canais temáticos estar dependente da capacidade financeira das famílias para subscreverem estes produtos, e da sua vontade em fazê-lo. Importa, por isso, perceber qual o espaço que os canais generalistas (em particular, os de serviço público) têm reservado, em termos de conteúdos de informação da atualidade, para as audiências infantis. Embora fosse importante apostar no 
reforço deste género de estudos, a análise da oferta televisiva para crianças tem merecido a atenção de vários investigadores (Pereira et al., 2009; Ponte, 1998), particularmente a partir do trabalho pioneiro desenvolvido por Maria Emília Brederode Santos (1991) sobre o programa infantil Rua Sésamo, exibido na RTP entre 1989 e 1997. De modo geral, estas pesquisas documentam a falta de diversidade e de qualidade na oferta televisiva para a infância dos canais generalistas. Uma destas investigações, encomendada pela Entidade Reguladora para a Comunicação Social (ERC) ao Centro de Estudos de Comunicação e Sociedade (CECS) da Universidade do Minho, concluiu que o género dominante na oferta televisiva para os mais novos, durante o período em estudo, era a "ficção animação" (Pereira et al., 2009: 87). A partir de uma análise que contemplou a caracterização da programação infantil e juvenil emitida pelos quatro canais nacionais (RTP1, RTP2, SIC e TVI), entre Setembro de 2007 e Outubro de 2008, os investigadores verificaram que esta categoria absorvia $67 \%$ da duração de programas emitidos, e correspondia a $83 \%$ do número de programas emitidos (idem: 87); pelo contrário, é preocupante que o género informativo não tenha sido objeto de referência.

Os espaços informativos desenhados especificamente para as audiências infantis tiveram lugar nos canais de serviço público, com os programas Jornalinho (1984-1987) e Caderno Diário (1990-2002), porém, a saída destes programas das grelhas criou, a nosso ver, uma falha expressiva no conjunto e na diversidade de espaços televisivos dirigidos aos mais novos, ainda que na atualidade pareça existir a tentativa de a preencher através da oferta do programa televisivo Diário XS e do portal Ensina, este apenas disponível online. Parece que, ao longo do tempo, particularmente nos canais de televisão públicos, os programas de informação de atualidade destinados aos mais novos foram-se abandonando, ou viram comprometida a sua qualidade, em detrimento da aposta noutro tipo de programação mais vocacionada para "entreter" do que para "informar".

Enfatizamos, a partir dos pressupostos expostos, a necessidade de existir uma aposta mais forte em espaços de informação de atualidade desenhados concretamente para as crianças, em especial, na televisão pública nacional. O entendimento do modo como as crianças se relacionam com as notícias, as suas formas de interação e de apropriação - problemáticas analisadas neste artigo - poderiam constituir-se como um importante ponto de partida para se conceberem esses espaços informativos que fossem adequados aos mais novos e que se preocupassem em ir ao encontro dos seus gostos e preferências.

\section{Estudo das práticas e dos modos de apropriação das notícias por crianças portuguesas}

\section{Questões e objetivos da investigação}

É com base na preocupação de mostrar aquilo que as crianças querem das notícias e, consequentemente, informar as empresas mediáticas e outros agentes sobre aspetos a considerar na conceptualização e desenvolvimento de espaços de informação concebidos a pensar nos mais novos, que este estudo assenta. Esta investigação tem, por isso, como objeto de estudo as crianças e as suas práticas de acesso e de consumo noticioso. Particularmente, pretendemos compreender, a partir da perspetiva das crianças (1) as formas e os hábitos de acesso às notícias, e (2) os modos de apropriação e a natureza das interações no que toca aos conteúdos de âmbito informativo. Neste sentido, definimos os objetivos seguintes: i) conhecer 
e descrever os meios de acesso às notícias, pelas crianças, e os seus hábitos de consumo; ii) identificar e compreender o tipo de interesse, as preferências, o conhecimento e as emoções que as crianças manifestam no envolvimento com as notícias; iii) compreender quais as variáveis mais significativas com implicação para o consumo de atualidade, por parte dos mais pequenos.

\section{Procedimento metodológico}

O universo da pesquisa é constituído por crianças a frequentar o $4^{\circ}$ ano do $1^{\circ}$ Ciclo do Ensino Básico (no ano letivo 2013/2014) das escolas do Concelho de Paredes, situado na periferia do Grande Porto. Integrado numa investigação mais ampla, este estudo, que apresenta um recorte dessa mesma investigação, combinou métodos quantitativos e qualitativos. Na primeira fase, administrámos inquéritos por questionário, de natureza exploratória, a 690 crianças com idades compreendidas entre os 8 e os 12 anos. A opção por este método tem origem no facto de ser útil na análise de um fenómeno social e no conhecimento de uma população, no que se refere aos modos de vida, comportamentos, valores e opiniões (Quivy \& Campenhoudt, 1992). O inquérito por questionário foi preenchido anonimamente pelas crianças, na sala de aula, na presença do investigador, tendo a sua aplicação decorrido entre os meses de Janeiro e Fevereiro de 2014. Após a administração dos inquéritos por questionário, todo o material foi supervisionado de modo a determinar se existia algum questionário que não fosse válido e a optar por determinadas decisões relativas ao tratamento dos dados. Dos 690 questionários aplicados, 5 foram eliminados pelo facto de se encontrarem incompletos no preenchimento, inviabilizando a codificação e a quantificação das respostas, pelo que a amostra final corresponde a 685 questionários válidos $(\mathrm{N}=685)$. Os dados foram tratados com recurso ao SPSS - versão 21 . Na apresentação dos resultados considera-se a frequência e a percentagem válida, atendendo somente aos casos válidos.

Num segundo momento da pesquisa, recorremos ao método qualitativo dos grupos de foco (GF). Especialmente no contexto da investigação sobre audiências, os grupos de foco são úteis para estudar as formas de interação e de inserção das mensagens mediáticas nos distintos setores da sociedade (Callejo, 2001). Num âmbito mais geral, pode dizer-se que este método é eficaz no estudo das atitudes e experiências em torno de um determinado assunto (Kitzinger \& Barbour, 1999), sendo particularmente vantajoso se intercalado com o recurso a metodologias quantitativas (Vallés, 1999).

Em termos de procedimento, foram dinamizadas seis sessões junto de crianças a frequentar duas turmas integradas em escolas diferentes, selecionadas a partir da amostra do inquérito por questionário. A escolha das turmas para a realização destes grupos foi feita junto dos professores que, durante a administração dos inquéritos por questionário, demonstraram recetividade em providenciar as condições necessárias, a nível de tempo e de espaço, à boa condução dos grupos. Os grupos de foco foram conduzidos nas duas turmas do $4^{\circ}$ ano das escolas EB1 de Lage-Parada, inserida no Agrupamento de Escolas Daniel Faria-Baltar, e EB1/JI de Serrinha, do Agrupamento de Escolas de Vilela, ambas integradas no Concelho de Paredes. No total, participaram 43 crianças com idades compreendidas entre os 9 e os 11 anos. A recolha dos dados decorreu nos dias 22 e 23 de Maio de 2014. O recurso aos grupos de foco foi feito após a análise dos dados obtidos através do inquérito por questionário, com o propósito de se corroborar resultados e de se aprofundar relações sugeridas pela análise quantitativa. 
No quadro seguinte, apresenta-se o desenho da amostra escolhida para a implementação dos seis GF levados a cabo nesta fase da pesquisa.

Quadro 1: Desenho dos grupos de foco

\begin{tabular}{|c|c|}
\hline $\begin{array}{l}\text { EB1 de Lage - Parada } \\
22 \text { de Maio de } 2014\end{array}$ & $\begin{array}{l}\text { EB1/JI de Serrinha } \\
23 \text { de maio de } 2014\end{array}$ \\
\hline GF2 & GF4 \\
\hline 3 Raparigas & 4 Raparigas \\
\hline 3 Rapazes & 4 Rapazes \\
\hline 9-11 anos & $9-10$ anos \\
\hline GF1 & GF5 \\
\hline 3 Raparigas & 5 Raparigas \\
\hline 4 Rapazes & 3 Rapazes \\
\hline 9-10 anos & $9-10$ anos \\
\hline GF3 & GF6 \\
\hline 4 Raparigas & 4 Raparigas \\
\hline 3 Rapazes & 3 Rapazes \\
\hline 9-10 anos & $9-10$ anos \\
\hline
\end{tabular}

Fonte: Elaboração própria

No que se refere à dinâmica de realização destes grupos, e uma vez que se trata de crianças pequenas, esta consistiu na realização de um conjunto de jogos e de atividades estruturadas, desenhados a partir de um guião previamente elaborado que teve por base os objetivos do estudo. Em termos de recursos, as atividades decorreram em torno da análise e da discussão de notícias selecionadas a partir dos jornais nacionais Diário de Notícias e Público. De referir, também, que no início das atividades as crianças foram convidadas a escolher um nome pelo qual queriam ser identificadas e, por este motivo, os nomes com os quais os participantes aparecem representados neste artigo, correspondem aos escolhidos por eles.

O registo dos grupos de foco foi realizado a partir de um gravador áudio, tendo-se posteriormente transcrito na íntegra as sessões. Após esta transcrição, fizemos uma leitura global dos dados e das notas de campo, com o objetivo de nos entrosarmos no sentido dos discursos e observarmos tendências gerais emergentes dos discursos dos participantes, que poderiam ser pertinentes para o enquadramento nos objetivos do estudo. Após esta primeira leitura, os dados foram analisados pelo NVivo e codificados de acordo com os objetivos previamente delineados. 


\section{Apresentação dos resultados}

\section{Análise quantitativa}

\section{Caracterização da amostra}

A amostra final é constituída por 685 indivíduos, dos quais 53\% pertencem ao sexo feminino e $47 \%$ ao sexo masculino. As crianças têm entre 8 e 12 anos de idade, sendo a média de idades de 9,02 anos.

Quanto às caracterização do agregado familiar, verifica-se que as famílias são constituídas principalmente pela mãe $(97,2 \%)$, pelo pai $(80,0 \%)$ e por irmãos (70,6\%). A média do número de irmãos é de 1,3397 . É de notar, ainda, a referência aos avós (19,9\%) e a tios (7,5\%). Na opção "Outro familiar", apenas 26 crianças, correspondentes a 3,8\% dos inquiridos, assinalaram a presença deste elemento, encontrando-se sobretudo a referência a primos, a padrinhos e ao padrasto/namorado da mãe.

No caso do conhecimento acerca do agregado familiar com pai e mãe, as respostas indicam que $80,1 \%$ dos inquiridos vivem com ambos os elementos, $18,7 \%$ vivem somente com a mãe e, ainda que com um peso muito pouco significativo, $1,2 \%$ (correspondente a 8 crianças) moram apenas com o pai $(n=673)$.

No que respeita aos níveis de qualificação dos pais, verifica-se que os estudos até ao $1^{\circ}$ Ciclo e ao $2^{\circ}$ Ciclo do Ensino Básico são as habilitações predominantes. Quanto à atividade profissional, verifica-se que no cômputo geral, tanto para o caso da mãe como o do pai, predominam as profissões ligadas a trabalhadores qualificados da indústria, construção e artífices, especificamente relacionadas com a transformação de alimentos, da madeira, do vestuário e outras indústrias e artesanato. Estas são enquadradas no setor secundário, relativo à transformação de matéria-prima em produtos (indústria, construção civil, fornecimento de água, gás e eletricidade).

No que concerne aos media a que as crianças têm acesso no lar, os dados obtidos mostram que a presença da televisão é predominante, seguindo-se a do computador, a da consola de jogos, e por último, a do telemóvel, com uma presença menos significativa, embora mais de metade das crianças afirme existir, pelo menos, um telemóvel em casa. Salientamos que a televisão está presente em 97,1\% dos lares da amostra, sendo que mais de metade beneficia do acesso ao serviço por subscrição, em comparação com o acesso aos quatro canais generalistas nacionais.

\section{Hábitos de consumo de notícias pelas crianças}

No que diz respeito à frequência com que as crianças acompanham as notícias, mais de metade afirmou que o faz todos ou quase todos os dias (58,9\%), 15,6\% fazem-no uma a duas vezes por semana, enquanto $22,4 \%$ acompanham as notícias raramente. Apenas 3,1\% das crianças nunca acompanham as notícias $(n=674)$. Não se verificaram, no entanto, diferenças entre os rapazes e as raparigas, no que se refere a esta variável $(a>0,05)$.

Os principais meios de acesso às notícias são, para mais de metade dos inquiridos, a televisão e os jornais, seguindo-se, por ordem decrescente, o computador, os pais, a rádio, as revistas, o telemóvel, os amigos, os professores e o jornal da escola. As crianças tinham, ainda, a possibilidade de mencionar 'Outros' meios 
de acesso a estes conteúdos, no entanto, apenas 20 inquiridos (3,5\%) o fizeram. Referiram, por exemplo, redes sociais (Facebook), espaços comerciais, outros familiares, e outras pessoas.

Gráfico 1: Meios de acesso às notícias $(\mathrm{N}=650)$

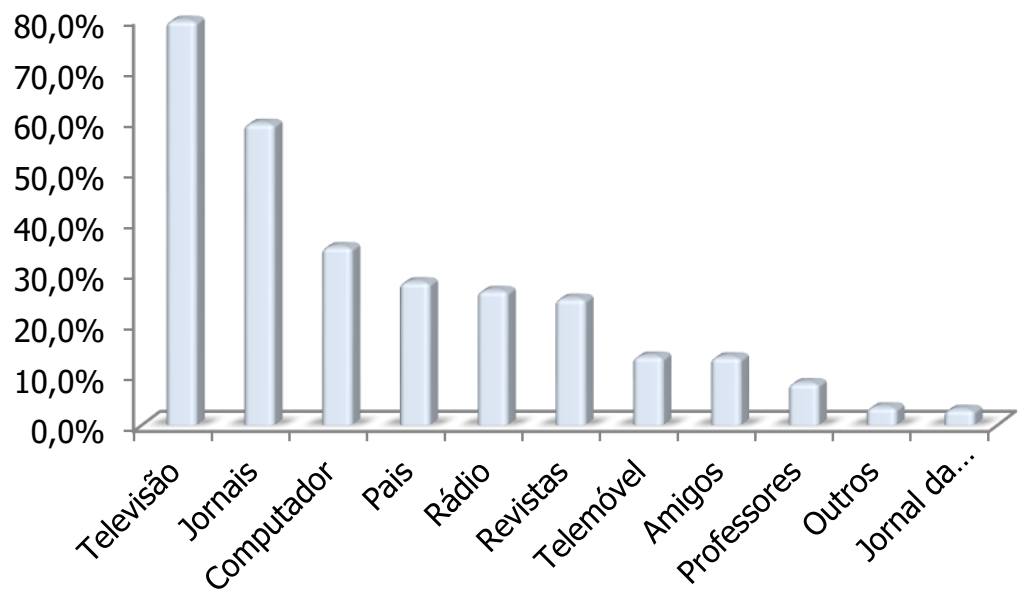

Fonte: Elaboração própria

Há, no entanto, diferenças entre os rapazes e as raparigas: estas acedem às notícias, sobretudo, através da rádio e de revistas; os rapazes sabem sobre estes conteúdos a partir do computador e dos amigos.

Encontramos, ainda, associações estatisticamente significativas entre a frequência de acompanhamento das notícias e os conteúdos televisivos favoritos dos inquiridos, nomeadamente, existe uma tendência para as crianças que preferem documentários e telejornais (e que não mostram preferência por filmes e desenhos animados), acompanharem as notícias todos ou quase todos os dias. Este aspeto torna-se particularmente interessante quando reparamos que mais de metade das crianças da amostra (58,9\%) diz acompanhar as notícias diariamente, fazendo-o sobretudo através da televisão, no entanto, quando as questionamos sobre os seus conteúdos favoritos, os desenhos animados ocupam as suas preferências, tendo o telejornal sido referido por apenas $18,9 \%$ dos inquiridos. Significa isto que na percentagem de crianças que acompanha todos ou quase todos os dias as notícias $(58,9 \%)$, mais de metade $(71,9 \%)$ preferia estar a ver outro tipo de conteúdos. No que concerne a este aspeto, outros estudos sobre as crianças e as notícias mostram que estes públicos assistem habitualmente às notícias através da televisão, mas isso não significa que gostem de fazê-lo, sendo este acompanhamento resultado da insistência dos pais ou uma forma de ocuparem os tempos livres (Buckingham, 2000). Por outro lado, pode também acontecer que os noticiários sejam acompanhados pela família, durante o tempo dedicado às refeições, fazendo com que a criança acabe igualmente por assistir aos mesmos, tal como já referido no enquadramento teórico.

Não queremos, com isto, dizer que as crianças não gostam de saber sobre as notícias. Como os dados obtidos permitiram apurar, 86,9\% dos inquiridos que afirmam acompanhar as notícias, gostam de o fazer; apenas $13,1 \%$ dos que acompanham, declaram não gostar $(n=664)$. Além disso, a percentagem de crianças que gosta de acompanhar estes tópicos é maior nas que acompanham todos ou quase todos os dias, como se conclui pela tabela seguinte. 
Tabela 1: Relação entre a frequência de acompanhamento das notícias e o gosto pelo acompanhamento das notícias $(\mathrm{N}=653)$

\begin{tabular}{|c|c|c|c|c|}
\hline \multicolumn{2}{|c|}{ Frequência de acompanhamento das notícias } & \multicolumn{2}{|c|}{$\begin{array}{l}\text { Gostar de acompanhar as } \\
\text { notícias }\end{array}$} & \multirow[t]{2}{*}{ Total } \\
\hline & & Sim & Não & \\
\hline $\begin{array}{l}\text { Todos ou quase todos os } \\
\text { dias }\end{array}$ & $\begin{array}{l}\text { Frequência } \\
\% \\
\text { Resíduo ajustado }\end{array}$ & $\begin{array}{l}381 \\
66,8 \% \\
8,3\end{array}$ & $\begin{array}{l}16 \\
19,3 \% \\
-8,3\end{array}$ & $\begin{array}{l}397 \\
60,8 \% \\
-\end{array}$ \\
\hline $\begin{array}{l}\text { Uma ou duas vezes por } \\
\text { semana }\end{array}$ & $\begin{array}{l}\text { Frequência } \\
\% \\
\text { Resíduo ajustado }\end{array}$ & $\begin{array}{l}88 \\
15,4 \% \\
-1,2\end{array}$ & $\begin{array}{l}17 \\
20,5 \% \\
1,2\end{array}$ & $\begin{array}{l}105 \\
16,1 \% \\
-\end{array}$ \\
\hline Raramente & $\begin{array}{l}\text { Frequência } \\
\% \\
\text { Resíduo ajustado } \\
\text { Frequência } \\
\%\end{array}$ & $\begin{array}{l}101 \\
17,7 \% \\
-8,6 \\
570 \\
100,0 \%\end{array}$ & $\begin{array}{l}50 \\
60,2 \% \\
8,6 \\
83 \\
100,0 \%\end{array}$ & $\begin{array}{l}151 \\
23,1 \% \\
- \\
653 \\
100,0 \%\end{array}$ \\
\hline
\end{tabular}

Nível de significância $(p<0,05)$

Fonte: Elaboração própria

No que concerne ao acompanhamento da atualidade pelas famílias dos inquiridos, os dados permitem verificar que na maioria destes agregados (82,9\%) as notícias são acompanhadas todos ou quase todos os dias. Em 8,3\% dos casos, o seguimento da atualidade faz-se raramente e, para 6,9\% das famílias, uma ou duas vezes por semana. Embora sejam poucos casos, em 13 agregados (correspondente a 1,9\%) nunca se acompanham as notícias $(\mathrm{n}=678)$.

Foram também encontradas relações estatisticamente significativas entre a frequência de acompanhamento das notícias pelas crianças e a frequência de acompanhamento das notícias pelos membros do agregado (Tabela 2), de tal modo que nas famílias que têm por hábito seguir estes conteúdos todos ou quase todos os dias, as crianças acabam, igualmente, por fazê-lo com a mesma periodicidade. 
Tabela 2: Relação entre a frequência de acompanhamento das notícias pelas crianças e a frequência de acompanhamento das notícias pelo agregado familiar $(\mathrm{N}=669)$

\begin{tabular}{|c|c|c|c|c|c|c|}
\hline \multirow{2}{*}{\multicolumn{2}{|c|}{$\begin{array}{l}\text { Frequência de acompanhamento } \\
\text { das notícias pelas crianças }\end{array}$}} & \multicolumn{5}{|c|}{$\begin{array}{l}\text { Frequência de acompanhamento de notícias pelo } \\
\text { agregado familiar }\end{array}$} \\
\hline & & $\begin{array}{l}\text { Todos ou } \\
\text { quase } \\
\text { todos os } \\
\text { dias }\end{array}$ & $\begin{array}{l}\text { Uma ou } \\
\text { duas vezes } \\
\text { por semana }\end{array}$ & Raramente & Nunca & Total \\
\hline $\begin{array}{l}\text { Todos ou quase } \\
\text { todos os dias }\end{array}$ & $\begin{array}{l}\text { Frequência } \\
\% \\
\text { Resíduo } \\
\text { ajustado }\end{array}$ & $\begin{array}{l}380 \\
68,5 \% \\
11,1\end{array}$ & $\begin{array}{l}7 \\
15,2 \% \\
-6,2\end{array}$ & $\begin{array}{l}4 \\
7,3 \% \\
-8,1\end{array}$ & $\begin{array}{l}3 \\
23,1 \% \\
-2,7\end{array}$ & $\begin{array}{l}394 \\
58,9 \% \\
-\end{array}$ \\
\hline $\begin{array}{l}\text { Uma ou duas } \\
\text { vezes por } \\
\text { semana }\end{array}$ & $\begin{array}{l}\text { Frequência } \\
\% \\
\text { Resíduo } \\
\text { ajustado }\end{array}$ & $\begin{array}{l}72 \\
13,0 \% \\
-4,1\end{array}$ & $\begin{array}{l}23 \\
50,0 \% \\
6,7\end{array}$ & $\begin{array}{l}7 \\
12,7 \% \\
-, 6\end{array}$ & $\begin{array}{l}2 \\
15,4 \% \\
, 0\end{array}$ & $\begin{array}{l}104 \\
15,5 \% \\
-\end{array}$ \\
\hline Raramente & $\begin{array}{l}\text { Frequência } \\
\% \\
\text { Resíduo } \\
\text { ajustado }\end{array}$ & $\begin{array}{l}93 \\
16,8 \% \\
-7,8\end{array}$ & $\begin{array}{l}15 \\
32,6 \% \\
1,7\end{array}$ & $\begin{array}{l}38 \\
69,1 \% \\
8,7\end{array}$ & $\begin{array}{l}4 \\
30,8 \% \\
7\end{array}$ & $\begin{array}{l}150 \\
22,4 \% \\
-\end{array}$ \\
\hline Nunca & $\begin{array}{l}\text { Frequência } \\
\% \\
\text { Resíduo } \\
\text { ajustado }\end{array}$ & $\begin{array}{l}10 \\
1,8 \% \\
-4,4\end{array}$ & $\begin{array}{l}1 \\
2,2 \% \\
-, 4\end{array}$ & $\begin{array}{l}6 \\
10,9 \% \\
3,4\end{array}$ & $\begin{array}{l}4 \\
30,8 \% \\
5,8\end{array}$ & $\begin{array}{l}21 \\
3,1 \% \\
-\end{array}$ \\
\hline Total & $\begin{array}{l}\text { Frequência } \\
\%\end{array}$ & $\begin{array}{l}555 \\
100,0 \%\end{array}$ & $\begin{array}{l}46 \\
100,0 \%\end{array}$ & $\begin{array}{l}55 \\
100,0 \%\end{array}$ & $\begin{array}{l}13 \\
100,0 \%\end{array}$ & $\begin{array}{l}669 \\
100,0 \\
\%\end{array}$ \\
\hline
\end{tabular}

Nível de significância $(p<0,05)$

Fonte: Elaboração própria

Os dados permitem ainda aferir que mais de metade das crianças $(60,5 \%)$ têm por hábito seguir as notícias na companhia do pai e da mãe $(n=664)$, sendo com estes elementos da família que conversam habitualmente sobre estes assuntos (63,2\% dos inquiridos afirmaram falar sobre as notícias com os pais). Apenas 10 crianças têm por hábito acompanhar as notícias sozinhas. 


\section{Análise qualitativa}

Apresentação dos participantes

Nos grupos de foco realizados, participaram 43 crianças - 23 raparigas e 20 rapazes - com idades compreendidas entre os 9 e os 11 anos.

Quanto à composição do agregado familiar, a maioria das crianças (39) está integrada em famílias de tipologia nuclear (presença de pai, de mãe e de irmãos), existindo quatro casos de famílias monoparentais. Quanto ao nível de escolaridade dos pais, a maioria (33) completou o Ensino Básico (regista-se um equilíbrio no número de pais com o $1^{\circ}$, o $2^{\circ}$ e o $3^{\circ}$ Ciclos), havendo cerca de oito com o Ensino Secundário e apenas um casal com o Ensino Superior. À exceção destes, que são professores, os restantes progenitores exercem profissões relacionadas com atividades de baixa qualificação, como eletricista, motorista de pesados, empregada doméstica, cabeleireira, mecânico, costureira, carpinteiro, e operário de construção civil. Existem oito situações de desemprego, e um de reforma. Há dois casos em que o pai se encontra emigrado. As crianças têm acesso ao computador Magalhães, a televisão, e a consola de jogos.

No que toca à ocupação dos tempos de lazer, sobressaem as seguintes atividades preferenciais: brincar, ver televisão, jogar jogos em consolas e computadores, e navegar na Internet.

\section{Preferências e escolhas em relação à atualidade}

No que se refere às preferências relativamente às temáticas representadas nas notícias, as crianças são unânimes na consideração dos tópicos com os quais gostariam de contactar mais frequentemente. As suas opções e gostos inclinam-se para os assuntos relacionados com desporto, música, acontecimentos da História (de Portugal e do mundo), cinema, educação, animais, ciência e meio ambiente. Os rapazes mostram, sobretudo, especial predileção pelo desporto (futebol), enquanto as raparigas apreciam acontecimentos sobre escolas e educação. Na opinião dos participantes, estes são os temas que interessam verdadeiramente às crianças, e admitem que procurariam aceder mais às notícias caso os mesmos tivessem mais espaço na agenda mediática. Por outro lado, as crianças assumem que o excesso de notícias sobre violência e política as afasta destes conteúdos, e que caso pudessem escolher, preferiam não ver retratados temas tão pessimistas e perturbadores.

$M$ (Moderadora)- Como é que acham que as notícias se poderiam tornar mais interessantes e atrativas para as crianças?

Rute- Sobre escolas.

Ronaldo- Sem violência.

Patrícia- Deviam meter coisas mais adequadas.

Demi- Deviam ter mais cuidado com quem vai ler o jornal, com quem vê televisão, porque quem vai ver pode ter pesadelos.

Bale- Não meter tantas notícias de mortes e acidentes, para as crianças poderem ler, e também usar palavras mais simples. 
Ronaldo- Não meter notícias de violência para não prejudicar a vida das crianças.

Patrícia- Os jornalistas também deviam fazer menos notícias de facas e de mortes.

Bale- Menos violência.

(GF2 - Grupo de Foco 2)

Há, todavia, uma tendência para os rapazes preferirem desporto (futebol), enquanto as raparigas mencionaram, principalmente, música e assuntos relacionados com escolas e educação. Outros estudos recentes, como o de Marôpo (2014) e o de Alon-Tirosh \& Lemish (2014), apontam para conclusões semelhantes. As crianças admitem, ainda, preferir acompanhar as notícias sobre acontecimentos do país, embora reconheçam que estão particularmente atentas quando se trata de assuntos relacionados com países que acolhem familiares emigrados. A atualidade internacional adquire, assim, significado para estes públicos, permitindo-os estar informados e "próximos" de lugares e de pessoas que se encontram fisicamente distantes.

M- E interessa-vos mais o que acontece em Portugal ou noutros países?

Patrícia- Em Portugal e noutros países. Na Suíça, porque a minha irmã está lá.

Ronaldo- Também gosto de ver sobre França porque o meu pai está lá.

Demi- E eu na polónia porque o meu padrinho ia para lá. Sabíamos se ele podia estar em perigo ou não.

Bale- $A$ mim é pela Europa toda porque o meu tio anda pela Europa toda.

Além dos assuntos das notícias de que mais gostam, as crianças são, também, capazes de enumerar os temas que não entram nas suas preferências. A análise qualitativa permite aferir o pouco interesse dos mais pequenos pelas questões políticas e económicas, tendo sido pouco ou nada significativo o interesse manifestado sobre estes assuntos. Vimos, inclusivamente, que outros estudos demonstram que este aparente desinteresse das crianças pela política e pela economia pode ter origem num certo silenciamento das suas vozes na discussão dos assuntos da sociedade, levando a um afastamento destas questões (Carter, 2007). Este tipo de notícias é percecionado pelas crianças como aborrecido e pouco interessante (Condeza et al., 2014), ainda que, por vezes, se trate de assuntos económicos e financeiros (como a crise e as suas consequências para as famílias) que as podem implicar, mais diretamente (Alon-Tirosh \& Lemish, 2014). Apesar deste desinteresse pela política e pela economia, as crianças reconhecem a sua importância para a sociedade. Nas respostas dos participantes, a economia aparece maioritariamente associada à crise e às (más) decisões políticas. As crianças estão informadas do que se passa, demonstrando esse conhecimento através das suas respostas, porém, observa-se também uma descrença e um desagrado para com os políticos e as suas ações, resultando num distanciamento e na pouca vontade em seguirem esses temas.

Daniela- Quando eu vejo as notícias é tudo sobre aumentar impostos.

TODOS- O Passos Coelho... Há menos pessoas a trabalhar, o aumento da gasolina, do gasóleo, os salários a diminuir.

Irina- E agora as eleições europeias. 
Daniela- $A$ política não tem muito interesse. Isso é mais para os adultos.

(GF1)

M- E interessam-se pelas notícias sobre política?

Fábio- Nem por isso.

Patrícia- Não.

Demi- Mas também interessa saber o que é que os políticos vão fazer ao nosso país.

M- E a crise económica, já ouviram falar?

TODOS- Simmmm.

M- $O$ que é que sabem sobre isso?

Fábio- Aquelas pessoas que ficam sem dinheiro para comer.

Demi- Há pessoas que não conseguem pagar as suas dívidas.

(...)

M- E quais são os temas nas notícias que menos vos interessam?

Bale- Política.

(GF2)

Os assuntos relacionados com política e economia são percecionados, pelas crianças, como enfadonhos, repetitivos e negativos. A opinião que criam sobre estes assuntos parece, também, ser influenciada pelas conversas com os familiares e os comentários que ouvem em casa, daí que, nos casos assinalados em seguida, as observações que fazem sejam pouco construtivas e ocasionais, retratando aquilo que os pais dizem.

Irina- Porque eles [políticos] dizem que vão melhorar as coisas e depois não fazem nada. Só querem luxo e passear.

M- Quem te disse isso?

Irina- $O$ meu pai.

M- $O$ que é que os pais vos dizem sobre isso?

Lara- Que eles [políticos] não conseguem melhorar. Que dizem que vão melhorar, mas depois não fazem nada.

(...)

"M- Em casa, fala-se sobre noticias de política e de crise?

Quaresma- O meu pai.

Ricardo-Sim.

Lara- O meu pai.

Vítor- Não.

Lara- O meu pai...enerva-se, começa a dizer palavrões.

Quaresma- É como o meu.

(GF1)

São todos uns ladrões [os políticos]. Mexem nos que recebem menos, mas não mexem no deles. 
M- Quem te disse isso?

Francisca- $A$ minha mãe.

(GF4)

Os comentários ocasionais e a pouca importância que, aparentemente, se dá a estes assuntos, nas famílias - porventura, descontentes e descredibilizadas face à ação política e económica - em detrimento de outros, podem justificar a alienação e o pouco interesse que as crianças manifestam em relação a estes tópicos. Além disso, de acordo com a generalidade dos participantes, estes temas são "mais para os adultos" e os jornalistas não têm a preocupação de adequá-los às crianças e aos seus interesses. Os depoimentos da Patrícia (GF2), do Fábio (GF2), da Demi (GF2), e do Hulk (GF4), permitem perceber que estes públicos consideram que não são vistos como verdadeiras audiências pelos media noticiosos, que transmitem os acontecimentos a pensar nos adultos e nas suas capacidades; razões que os levam a estarem pouco atentos a estas notícias e a sentirem-se desmotivados para o consumo das mesmas.

Patrícia- Eu acho que eles [jornalistas] pensam mais nos adultos do que nas crianças.

Fábio- Porque eles pensam que as crianças raramente veem as notícias. Se eles pensassem nas crianças, não punham certas palavras.

Demi- Eu acho que eles preocupam-se mais em informar pessoas do que com crianças.

Patrícia- Eu acho que os jornalistas deviam por notícias mais adequadas para as crianças.

Os jornalistas pensam que as crianças não dão utilidade às notícias e que enquanto estão a ver as notícias estão a fazer outras coisas. (Hulk, GF4)

A falta de interesse pelos temas políticos e económicos parece ter, também, origem no facto de os pontos de vista das crianças acerca destes assuntos não terem lugar no espaço doméstico, mediático e social. As respostas dos participantes apontam para a perceção de que estes não têm capacidade para formular ideias com valor sobre assuntos tão importantes, num discurso que parece ter vindo a ser-lhes incutido e que se encontra enraizado na pouca valorização que atribuem às suas possíveis interpretações.

Hulk- Ainda não percebemos bem as coisas.

M- Acham mesmo que não percebem bem as coisas?

Fernando- Foi a minha mãe que me disse.

Francisca- Nós ainda somos menores e não sabemos como é que os políticos vão ajudar o país. (GF4)

Precisamos de ter mais idade para compreender melhor as coisas. (Nathy, GF5)

As crianças não percebem nada. Os adultos já percebem mais. (Quaresma, GF1) 
Além dos temas relacionados com a política e a economia, de modo geral, as crianças mostram que não gostam de acompanhar notícias violentas, pois consideram-nas "horrorosas", "assustadoras" e "tristes". $\mathrm{Na}$ sua opinião, os media deveriam estar mais atentos e preocupados com os públicos infantis, de modo a disponibilizar conteúdos informativos mais adequados aos seus interesses e capacidades. As respostas do Fábio (GF2), da Francisca (GF4), e da Demi (GF2) apontam para uma perceção das notícias como retratando, na maioria das vezes, assuntos negativos (como crimes, mortes e violência), e aborrecidos (como a política e a economia).

[Os jornalistas] deviam pensar melhor nas imagens e não meter palavras tão assustadoras, meter palavras mais simples. (Fábio, GF2)

Está sempre a dar [nas notícias] crimes e violência. Eu não gosto disso! Prefiro ver outras coisas. (Francisca, GF4)

[Nas notícias] É só política, política. (Demi, GF2)

Apesar disso, as crianças reconhecem que há certas notícias de que não gostam (como crimes) que são importantes que o público conheça, assumindo-se, a partir dos seus discursos, que uma das funcionalidades do jornalismo é informar as pessoas sobre aquilo que se passa no mundo, independentemente do teor negativo das suas matérias. Por esse motivo, concluímos que, para os mais pequenos, as notícias elaboradas a pensar nos públicos infantis não deveriam reduzir-se unicamente aos assuntos que incorporam as suas preferências, podendo integrar outras temáticas - ainda que potencialmente traumáticas - porém, dadas a conhecer de modo diferente, mais simplista e com palavras "que não assustem". O tipo de linguagem assume-se, assim, como um aspeto a considerar na produção de conteúdos informativos a pensar nos mais novos. As crianças solicitam o recurso a vocabulário mais adequado ao seu entendimento e mais cuidado na forma de descrever os acontecimentos.

M- Se houvesse um telejornal feito a pensar nas crianças, e para as crianças, como é que acham que deveria ser?

Francisca- Com palavras mais simples.

M- Mas as notícias podiam ser outras, ou as que veem normalmente no telejornal, mas contadas de outra forma?

Francisca- As mesmas, mas contadas de outras forma.

Hulk- Mas não devia mostrar tanta violência e crimes.

Francisca- Mas as crianças também têm o direito de saber sobre as coisas, e é importante estarem protegidas.

Hulk- Pois...

As imagens são, também, fundamentais para a compreensão e a atração pelas notícias, de tal modo que nas respostas dos participantes foi notória a importância que estes públicos atribuem à imagem, em 
detrimento do texto. Nomeadamente a imagem em movimento, e a cores, com que contactam frequentemente pelas notícias da televisão, parece exercer um verdadeiro fascínio sobre os mais novos; motivos que podem conduzir a que se sintam mais atraídos para o consumo de notícias por via deste médium, e que fazem com que um dos aspetos mais significativos na relação que estabelecem com as notícias seja, como aferimos, o impacto e o envolvimento, sobretudo do ponto de vista emocional.

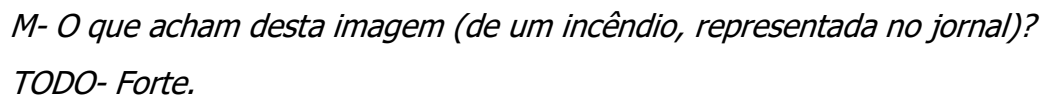

Sabemos, a este respeito, que os media recorrem frequentemente à cobertura visual dos acontecimentos, muitas vezes no momento da sua ocorrência, saturando as notícias com imagens apelativas e que amplificam a presença da violência no mundo real, de modo a dramatizar os acontecimentos e a apelar à empatia dos públicos. As crianças admitem que as imagens, por vezes, as impressionam, no entanto, valorizam o seu papel enquanto auxiliares na compreensão dos acontecimentos e na credibilidade com que conotam os mesmos. Além disso, os seus depoimentos permitem perceber que as imagens possibilitam experienciar, através da imaginação, as situações retratadas.

As imagens permitem imaginar melhor como as coisas acontecem. (Hulk, GF4)

M- Nas notícias, as imagens servem para alguma coisa?

Bale- Sim, para vermos melhor sobre o que está a acontecer.

M-Se pudessem escolher entre uma notícias só com texto, e outra só com imagem, qual preferiam? Bale- Imagem.

Fábio- Imagem.

Demi- As imagens explicam melhor. 


\section{Conclusão e reflexão final}

Como os dados obtidos permitem concluir, as notícias fazem parte do quotidiano das crianças, e estas seguem estes conteúdos habitualmente na companhia da família, principalmente do pai e da mãe. A televisão é o principal meio de acesso a estes assuntos. Apesar da evolução das tecnologias da informação e da comunicação, os media tradicionais, particularmente a televisão, continuam a ser a principal fonte de acesso aos acontecimentos do mundo pelas famílias, fazendo com que as crianças acabem por acompanhálos, igualmente, através deste meio. Ainda que os resultados não possam ser extrapolados para a generalidade da população infantil, em Portugal, permitem perceber que as crianças procuram as notícias para estarem informadas sobre os acontecimentos do país e do mundo, e para acompanharem os temas que mais Ihes agradam.

Apesar do contacto frequente com as notícias, concluímos, à semelhança de outros estudos já mencionados (Alon-Tirosh \& Lemish, 2014; Carter, 2007), que os públicos infantis desejam ter espaços de informação mais adequados e que Ihes expliquem os assuntos que acontecem no mundo de uma forma que os cative e que possam compreender. Os temas importantes para o quotidiano das sociedades, particularmente relacionados com assuntos políticos e económicos, são percecionados como tópicos importantes, porém, pelo facto de serem dados a conhecer "à medida dos adultos", tornam-se enfadonhos e de difícil compreensão para os mais pequenos. Por outro lado, há também a perceção generalizada de que a agenda mediática dá demasiada cobertura a tópicos chocantes e violentos, constituindo-se estes como assuntos que são do desagrado dos mais jovens, ainda que estes reconheçam a sua importância.

Consideramos, por isso, que seria importante que a televisão, em particular, - meio que continua a ser muito importante para as crianças e com o qual estas criam uma ligação, por conta do fascínio pela imagem - se assumisse como espaço de referência no entendimento da atualidade e do mundo, para os mais pequenos, proporcionando-Ihes espaços informativos com qualidade e com diversidade de tópicos. Não queremos, com isto, defender a rejeição dos programas de entretenimento, até porque estes continuam a ser muito importantes para as crianças. O que entendemos é que poderia haver um esforço no equilíbrio dessa oferta com a disponibilização de programas de foro informativo e de natureza sociocultural e cívica, que contribuíssem para o conhecimento e o esclarecimento dos assuntos da atualidade, qualquer que seja a sua natureza. Além disso, importa notar que estes programas poderiam funcionar como um interessante contributo para a literacia para as notícias, ao proporcionarem às crianças formas mais eficazes de olhar o mundo, e de refletir, de forma mais esclarecida, sobre as questões da sociedade que, por vezes, se tornam de difícil compreensão para os mais novos quando são dadas a conhecer através de programas de notícias dirigidos a um público mais abrangente. Esta questão poderia estender-se a todos os canais, inclusivamente aos temáticos, uma vez que são estes que têm a possibilidade de emitir, durante todo o dia, programação pensada especificamente para este segmento; porém, talvez seja mais difícil romper com os interesses comerciais destas cadeias televisivas e dos seus produtores, pelo que a televisão do Estado poderia abrirse a essa possibilidade e assumir essa oferta, procurando, até, sinergias com o online. Como notamos no ponto 2., há casos de sucesso noutros países, no entanto, surpreendentemente, ao nível do plano normativo em Portugal, o Contrato de Concessão do Serviço Público de Rádio e de Televisão, agora em vigor, deixou de contemplar a disponibilização deste tipo de programas aos públicos infantojuvenis, tratando esta questão de modo mais abrangente. Seria, de facto, saliente pensar-se com seriedade nesta problemática, abrindo a 
possibilidade às audiências infantis de se constituírem como verdadeiros públicos das notícias e, em simultâneo, verem efetivado o seu direito à informação, tal como legitimado pela Convenção sobre os Direitos da Criança (Unicef, 1989).

\section{Referências Bibliográficas}

Alon-Tirosh, M. \& Lemish, D. (2014). "If I Was Making the News": What do Children Want From News?. Participations - Journal of Audience \& Reception Studies, 11(1), 108-128.

Araus, A.T. (2011). Qué Ven los Niños?. In P.F. Martínez (ed.), Los Niños y El Negocio de la Televisión: Programación, Consumo y Lenguage (pp.90-104). Sevilha: Comunicación Social.

Brederode Santos, M.E. (1991). Aprender com a Televisão: O Segredo da Rua Sésamo. Lisboa: TV Guia Editora.

Buckingham, D. (2000). The Making of Citizens: Young People, News and Politics. London: Routledge.

Callejo, J. (2001). Investigar las Audiencias: Un Análisis Cualitativo. Barcelona: Paidós.

Carrero, J.S. (2008). "Telediario Infantil": Recurso para el Aprendizaje en TV. Comunicar, 16(31), 153-158.

Carter, C. (2007). Talking about My Generation: A Critical Examination of Children`s BBC Newsround Web Sites Discussions About War, Conflit and Terrorism. In D. Lemish \& M. Götz (eds.), Children and Media in Times of War an Conflit (pp.121-142). USA: Hampton Press.

Condeza, R., Bachmann, I. \& Mujica, C. (2014). News Consumption among Chilean Adolescents: Interest, Motivations and Perceptions on the News Agenda. Comunicar, 22(43), 55-64.

Convenção sobre os Direitos da Criança, adotada pela Assembleia Geral das Nações Unidas em 20 de Novembro de 1989 e ratificada por Portugal em 21 de Setembro de 1990.

Delorme, M.I.C. (2013). As Crianças e as Notícias da Televisão. Educação em Revista, 29 (1), 205-223.

Endestad, T., Heim, J., Kaare, B., Torgersen,L. \& Brandtzaeg, P.B. (2011). Media User Types Among Young Children and Social Displacement. Nordicom Review, 32(1), 17-30.

Garmendia, M., Casado, M.A. \& Jiménez, E. (2012). Oportunidades y Riesgos para los Menores en Europa: La Red EU Kids Online. In A. Jiménez (ed.), Comunicación, Infancia y Juventud (pp.57-74). Barcelona: Editorial UOC.

Götz, M. (2007). "I Know That It Is Busch `s Fault": How Children in Germany Perceived the War in Iraq. In D. Lemish \& M. Götz (eds.), Children and Media in Times of War and Conflict (pp.15-36). USA: Hampton Press.

Gunter, B., Furnham, A. \& Griffiths, S. (2000). Childen`s Memory for News: A Comparison of Three Presentation Media. Media Psychology, (2), 93-118.

Hujanen, J. \& Pietikäinen, S. (2004). Interactive Uses of Journalism: Crossing Between Technological Potential and Young People`s News-Using Practices. New Media and Society, 6(3), 383-401.

Kitzinger, J. \& Barbour, R.S. (1999). Introduction: The Challenge and Promise of Focus Groups. In J. Kitzinger \& R. S. Barbour (eds.), Developing Focus Groups Research: Politics, Theory and Practice (pp-1-20). London: Sage Publications.

Kruuse, K., \& Kalmus, V. (2016). Supernatural creatures, accidents and war: Young children's televisionrelated fears and coping strategies. Television \& New Media, 18(3), 252-268. 
Lemish, D. (2007). "This is Our War:" Israeli Children Domesticating the War in Iraq. In D. Lemish \& M. Götz (eds.), Children and Media in Times of War and Conflit (pp.57-74). USA: Hampton Press.

Marôpo, L. (2014). Identidade e Estigmatização: As Notícias nas Percepções de Crianças e Jovens de um Bairro de Realojamento. Análise Social, 49 (1), 104-127.

Molen, J.H.W.V.D. \& Konijn, E.A. (2007). Dutch Children`s Emotional Reactions to News About the War in Iraq: Influence of Media Exposure, Identification and Empathy. In D. Lemish \& M. Götz (eds.), Children and Media in Times of War an Conflit (pp.75-98). USA: Hampton Press.

Molen, J.H.W.V.D. \& Vries, M.D. (2003). Violence and Consolidation: September 11th 2001 Covered by the Dutch Children`s News. Journal of Educational Media, 28(1), 5-19.

Nikken, P. \& Götz, M. (2007). Children`s Writings on the Internet About the War in Iraq: A Comparison of Dutch and German Submissions to Guestbooks on Children`s TV News Programs. In D. Lemish \& M. Götz (eds.), Children and Media in Times of War an Conflit (pp.99-120). USA: Hampton Press.

Pereira, S., Pinto, M. \& Pereira, E. (2009). A Televisão e as Crianças: Um Ano de Programação na RTP1, RTP2, SIC e TVI. Lisboa: Entidade Reguladora para a Comunicação Social.

Ponte, C. (1998). Televisão para Crianças: O Direito à Diferença. Lisboa: Escola Superior de Educação João de Deus.

Quivy, R. \& Campenhoudt, L.V. (1992). Manual de Investigação em Ciências Sociais. Lisboa: Gradiva.

Rebelo, J., Ponte, C., Férin, I., Malho, M.J., Brites, R. \& Oliveira, V. (2008). Estudo de Recepção dos Meios de Comunicação Social. Lisboa: Entidade Reguladora para a Comunicação Social.

Silveira, P. (2016). Crianças e Notícias: Construindo Sentidos sobre a Atualidade e o Mundo. Tese de Doutoramento em Ciências da Comunicação. Universidade do Minho. Retirado de http://repositorium.sdum.uminho.pt/handle/1822/42445.

Silveira, P. (2019). The news and Its Impact on Portuguese Children `s Perspectives. Journal of Children and Media, 13(1), 89-105.

Tavares, S. (2008). A Programação para Crianças na Televisão por Cabo em Portugal: Estudo da Oferta dos Canais Temáticos Infantis em 2005. Dissertação de mestrado. Universidade do Minho. Retirado de http://repositorium.sdum.uminho.pt/handle/1822/13765.

Vallés, M. (1999). Técnicas Cualitativas de Investigación Social: Reflexión Metodológica y Práctica Profesional. Madrid: Editorial Síntesis. 